\title{
NECESIDAD DE LOS SACRAMENTOS EN ESTE TIEMPO DE PANDEMIA
}

\begin{tabular}{c} 
César Buendia* \\
$\begin{array}{r}\text { Universidad Católica Sedes Sapientiae } \\
\text { cbuendia@ucss.edu.pe }\end{array}$ \\
\hline
\end{tabular}

Fecha de recepción: agosto de 2020

Fecha de aceptación: diciembre de 2020

Resumen: Este artículo establece un diálogo entre la tradición de diferentes Padres de la Iglesia, la enseńanza doctrinal de los sacramentos y la coyuntura actual de la pandemia. Ante una situación tan adversa para los rituales y prácticas públicas de fe, el autor considera necesario volver sobre la dimensión de aquel milagro en el mundo moderno que representan los sacramentos, en especial la eucaristía y la confesión. Abordará también la

* César Buendía es sacerdote y doctor en Teología por la Facultad de Teología de Valencia. Es licenciado en Pedagogía por la Universidad de Valencia. Sus principales temas de estudio han sido la Teología de la Liberación Latinoamericana y la Teología de los sacramentos en santo Tomás de Aquino. Ha sido, durante varios ańos, secretario de la Comisión del Clero de la Conferencia Episcopal Peruana. Ha ejercido la docencia en la Facultad de Teología Pontificia y Civil de Lima, en el ISET Juan XXIII y en la Facultad de Teología Redemptoris Mater. Actualmente, es rector de la Universidad Católica Sedes Sapientiae, en donde dicta las cátedras en temas teológicos y lenguas, y forma parte del Gabinete Pedagógico de la Facultad de Ciencias de la Educación y Humanidades de esta casa de estudios. De igual modo, desde hace más de una década, ha desempeñado una incesante labor pastoral en Lima Norte. 
perspectiva del ateísmo y la postura protestante, además de la superación que en torno de ellas ha marcado históricamente la doctrina de la Iglesia en materia sacramental. La reflexión sobre la gracia y los sacramentos también tendrá un lugar importante en estas páginas con el fin de alentarnos a la búsqueda de estos dones que en tiempos tan difíciles se topan ante restricciones desalentadoras.

Palabras clave: Sacramentos, pandemia, gracia sacramental, Padres de la Iglesia, ateísmo, protestantismo.

\section{NECESSITY OF SACRAMENTS IN THIS PANDEMIC TIME}

Abstract: This article establishes a dialogue between the tradition of different Church Fathers, the doctrinal teaching of the sacraments and the current situation of the pandemic. Faced with such an adverse situation for rituals and public practices of faith, the author considers it necessary to return to the dimension of that miracle in the modern world represented by the sacraments, especially the Eucharist and confession. He will also address the perspective of atheism and the protestant position, in addition to the overcoming that around them have historically marked the Church's doctrine on sacramental matters. Reflection on grace and the sacraments will also have an important place in these pages in order to encourage us to seek these gifts that in such difficult times are faced with daunting restrictions. Keywords: Sacraments, pandemic, sacramental grace, Church Fathers, atheism, protestantism. 


\section{1. "Lo que era Jesucristo ahora lo vivimos en los sacramentos"}

stas palabras que dan título al apartado, dichas por san León, tienen
su lugar específico, de modo máximo, en la presencia eucarística.
Dice san Ambrosio:

La palabra de Cristo que pudo crear de la nada lo que no existía, ¿no puede transformar en algo diferente lo que existe? No es menos dar a las cosas una naturaleza del todo nueva que cambiar lo que tienen.... Este cuerpo que 'damos a luz' (conficimus) sobre el altar es el cuerpo nacido de la Virgen. ... Es, ciertamente, la verdadera carne de Cristo que fue crucificada, que fue sepultada; es, pues, verdaderamente el sacramento de su carne... El mismo Señor Jesús proclama: 'Esto es mi cuerpo'. Antes de la bendición de las palabras celestes se usa el nombre de otro objeto, después de la consagración se entiende cuerpo. (2005, pp. 52-53)

Por su parte, ha sido oportunísima, providencial en este tiempo de pandemia la declaración de la Comisión Teológica Internacional:

No pocos católicos se han hecho a la idea de que la sustancia de la fe radica en vivir el evangelio, despreciando lo ritual como ajeno al corazón del evangelio y, consecuentemente, ignorando que los sacramentos impulsan y fortalecen la vivencia intensa del mismo evangelio. (2020, n. 8)

Dado que la revelación sucede de modo sacramental, el elemento sacramental ha de permear toda la existencia creyente y la misma fe. En efecto, de la sacramentalidad de la revelación, de la gracia y de la Iglesia se sigue la sacramentalidad de la fe, como acogida 
y respuesta a esta revelación (DV 5). La fe se genera, cultiva, crece y se expresa en la sacramentalidad, en ese encuentro con el Dios vivo a través de las mediaciones por las que Él mismo se dona. Así, la sacramentalidad es el hogar de la fe. Pero también, en esta dinámica la fe se manifiesta como la puerta (cf. Hch 14,27) de acceso a lo sacramental: al encuentro y a la relación con el Dios cristiano en la creación, en la historia, en la Iglesia, en la Escritura, en los sacramentos. Sin la fe los símbolos de índole sacramental no actualizan su significación, sino que enmudecen. La sacramentalidad implica una comunicación y una comunión personal entre Dios y el creyente por medio de la Iglesia y las mediaciones sacramentales. (2020, n. 19; cursivas en el original)

El texto de la Comisión insiste en vivir los sacramentos desde la fe, es decir, creyendo en ellos a Dios, creyendo a Dios en ellos, donde está presente el mismo Dios. Porque en ellos quiere estar presente, en un diálogo donde se da por parte de Dios una respuesta a la sed infinita del hombre de E encontrarse con el sentido de su vida, el amor de Dios.

La continuidad entre la Palabra, la Historia de Salvación y los mismos Sacramentos, les quita a estos todo carácter mágico porque también evita considerar, simplemente, al ser humano, al creyente, como un sujeto pasivo. Hay un diálogo, donde Dios está.

Desde la Ilustración, el Racionalismo y los deístas ingleses, Dios está convertido en un mudo o un Ausente. Ya lo era prácticamente para los herederos del nominalismo. Quizá por ello y, desde ese presupuesto, la Iglesia y lo que ella significa chocaron de frente con una concepción en que el hombre es la medida de todo. Algo así vemos en Lutero. 
El caso del ateísmo no se deriva de la falta de coherencia de las pruebas anteriores de la existencia de Dios. Son coherentes. Sino que se ha dado una desconfianza fundamental de la capacidad del hombre de acceder a la realidad. Se ha separado al ser humano de la verdad. Y, lógicamente, el resultado de todo ello no es que el hombre ya no sea un interlocutor solo de Dios, es que no lo es ni siquiera del mundo. No sabe nada de nada. No es simplemente que, como en la caverna de Platón, solo ve sombras. Es que ni siquiera sabe si ve las sombras. Evidentemente, la sospecha de que el hombre inventa aquello de lo que no tiene constancia directa hace a Dios impenetrable. Y, lógicamente, el dios resultante no vuelve al hombre imagen suya. Más bien, ese dios sería imagen del hombre ${ }^{1}$. Sería interesante a este respecto hacer toda una historia del ateísmo contemporáneo sin perderse en las intrincadas sendas por las que cada uno ha discurrido.

Todo se enfrenta con la Revelación. Si Dios ha entrado en la historia, ya no hay motivo para desconfiar de la imagen de Dios. Él mismo ha presentado su imagen. El ateísmo contemporáneo, de raíces prometeicas, hijo del racionalismo, no es la mejor base para comprender la fe, puesto que reduce a Dios, y lógicamente, la relación con Él, o a mera ilusión, como hacen los maestros de la sospecha, o a algo peor, a un ser del que lo mejor es defenderse.

El mundo actual, con su soberbia y su ciencia, intenta asegurar al hombre contra Dios. Y la pandemia nos ha demostrado que solo somos

1 Jenófanes de Colofón ya veía a los dioses homéricos como simples ilusiones de los hombres: "Pero los mortales se imaginan que los dioses han nacido y que tienen vestidos, voz y figura humana como ellos... Los Etíopes [dicen que sus dioses son] de nariz chata y negros; los tracios que tienen los ojos azules y el pelo rojizo... Pero si los bueyes, [caballos] y leones tuvieran manos o pudieran dibujar con ellas y realizar obras como los hombres, dibujarían los aspectos de los dioses y harían sus cuerpos, los caballos semejantes a los caballos y los bueyes a bueyes, tal como si tuvieran la figura correspondiente [a cada uno]" (1981, pp. 281; 295; 304). 
criaturas. Que la soberbia debe ser sustituida por la confianza, para no caer en la desesperación o en el fatalismo, también griego. Y la confianza, y no la resignación, debe tener sus motivos. Y el motivo es haber conocido a Dios en Cristo. Esto es lo que dice Benedicto XVI en la Spe Salvi con maestría inigualable.

La negativa a creer en el milagro por parte del mundo moderno no proviene del milagro en sí, sino de la incapacidad para aceptar el hecho de la revelación. Y eso no por desconfianza de la posibilidad de Dios, o por mejor decir, la imposibilidad del mundo sin la existencia de Dios, sino porque se estima que la supervivencia del hombre y de su poder es imposible si se habla de la dependencia de Dios. Dios supera al hombre por todas partes. Pero eso, que significa que el hombre, que es un niño que mira a su Padre, no puede ser aceptado por el que se ha puesto en el lugar del juez.

Pero los sacramentos, precisamente porque los tenemos delante, son más escandalosos y más increíbles para algunos. Los sacramentos se resisten al puro racionalismo que excluye lo trascendente. Y, además, sus ministros son simples seres humanos, por ańadidura pecadores, aunque no siempre sean pecadores, ni en todo momento estén en pecado.

Los sacramentos son un escándalo para el mundo, porque reconocemos en ellos a Dios, presente, en la vida, en la historia, en los acontecimientos y en la Iglesia. Y ahora. Los hechos del Jesús histórico quizá para algunos queden en el pasado, en el oscuro túnel de la historia, y del pasado, del que, como no se queja, se puede decir cualquier mentira, cualquier suposición o cualquier teoría, pero los sacramentos están ahí delante, y piden la fe aquí y ahora. Por eso escandalizan. Por eso, porque la actualidad obliga a la urgencia en la fe, se les ofrece una resistencia inusitada. 
Y los sacramentos son, como actos humanos de diálogo, actos de alianza, que comprometen al hombre ${ }^{2}$. También por eso exigen la fe como una obediencia a la realidad que los sacramentos proponen. En ellos vemos a Dios con los ojos de la fe.

\section{La doctrina sacramental, tal como la Iglesia la ha recibido}

hora pasemos a recordar la doctrina sacramental, tal como la Iglesia
la ha recibido. Los sacramentos son, a la vez, instrumentos y signos
de la gracia santificante. Otorgan la gracia que significan. Por "sacramento" se entiende lo visible del acto sacramental. Se llama sacramento al gesto y a las palabras a la vez. Es el signo.

Se llama, sin embargo, en latín "res" y en castellano "realidad" a la gracia que otorgan los sacramentos, los signos. Se trata, principalmente, de la gracia santificante o habitual que, según la doctrina tradicional, es inherente, es accidental ${ }^{3} \mathrm{y}$ es permanente.

La gracia santificante es aquella gracia por la que, como hijos de Dios, estamos en comunión con la Santísima Trinidad, por la inhabitación

2 "Sacramentum era... el juramento y el compromiso con los dioses y con el ejército, e implicaba la exigencia de fidelidad a un determinado estilo de vida. Sacramento era la posibilidad y la responsabilidad de una determinada manera de vivir en la milicia romana; así este término tenía la posibilidad de incorporar el compromiso fiel de Cristo con el Padre (Fil 2,5-7), de la Iglesia con Cristo (Ef 5,21-24), y del cristiano con Cristo y la Iglesia en or-den de que pueda realizarse su salvación personal (I.Cor 9,24-10,13)" (Tratado general de los sacramentos, s.f.). Este aspecto de consagración, por la que Dios toma al hombre en el sacramento, y el hombre también se compromete con Dios, asusta. Sin embargo, es la condición necesaria para que Dios pueda transformar al hombre y elevarlo hasta la comunión con Él.

3 Accidental en sentido filosófico. Porque lo sustancial es ser hombre, accidental pues no todo hombre lo es, es la santidad que nos da la gracia. 
en el alma del Espíritu Santo, que nos hace vivir como hijos del Padre y nos hace compartir la vida eterna ${ }^{4}$.

En el estudio de esta gracia hay que recordar la posibilidad de crecer en gracia. En este sentido, vale la pena pensar en las dos imágenes de la gracia barajadas en Trento, la de Seripando, general de los agustinos, y la que finalmente triunfó en Trento.

Los partidarios de la doctrina de la doble justicia, es decir, de Seripando, que hablan de que el hombre redimido queda en parte pecador y en parte santo, justo internamente pero necesitado exteriormente de una parte de justicia imputada, defendida por el ya nombrado cardenal Seripando, los teólogos Pflug, Pighi y Gropper, y los cardenales Pole, Contarini y Cervini;

4 Es necesario distinguir entre ser hijos de Dios, que nunca se pierde, pues corresponde al carácter bautismal, y tener la gracia, que sería algo así como estar en la casa del Padre de la parábola del Hijo Pródigo. Es accidental, pero es lo más importante de la vida.

5 Los partidarios de la doctrina de la doble justicia, es decir, de Seripando, que hablaban de que el hombre redimido queda en parte pecador y en parte santo, justo internamente pero necesitado exteriormente de una parte de justicia imputada, defendida por el ya nombrado cardenal Seripando y los teólogos Pflug, Pighi y Gropper: "Antes de la reunión del Concilio de Trento, algunos católicos se esforzaron para crear una atmósfera de entendimiento con los protestantes. La "fórmula concordiae" (fórmula de concordia) que creían aceptable para católicos y protestantes fue la de la doble justicia, apoyándose en ciertas expresiones de autores medievales. S. Bernardo, había afirmado que "iustitia hominis est indulgentia Dei” (La justicia del hombre es la indulgencia de Dios) (PL. 183, 892). Una tendencia análoga se encuentra en las corrientes del pensamiento de la Devotio Moderna, particularmente en la Imitación de Cristo de Tomás de Kempis, quien gusta de repetir que Cristo es el solo motivo de confianza en la hora de la muerte. Sobre esta corriente teológica se apoya la Escuela de Colonia, representada por Pighi y su discípulo Gropper, y en el Concilio de Trento por el cardenal Contarini, Legado pontificio, y por Jerónimo Seripando, general de los agustinos. La línea, pues, de la escuela de Colonia al respecto es la siguiente: "Nuestra" justicia es doble. Una interior, gratuita desde luego, afirmada contra el puro extrinsecismo de los protestantes; pero esta justicia interior, causa formal de la justificación, es imperfecta y, en consecuencia, tiene necesidad de un complemento. Este complemento, siendo también causa formal de nuestra justificación, es exterior a nosotros por cuanto que es la misma justicia de Cristo que se nos imputa” (Vilaplana Molina, A. apuntes de clase, s.f.). 
esta postura es distinta de la luterana que defiende la inexistencia de la gracia inherente al hombre, y que dice que el hombre redimido queda, sin embargo, internamente, todo pecador $y$, con la imputación de la gracia, externamente todo santo, y es distinta de la finalmente consagrada en el concilio de Trento que habla de un pecador redimido y un pecado perdonado, con una gracia interna, inherente al hombre, pero no en parte interior y en parte exterior, sino si bien capaz de crecer, totalmente interior y capaz de volver santo a todo el hombre, aunque no totalmente. Ello justifica que digamos que el hombre es capaz de crecer en gracia.

Como se mencionó anteriormente, la teoría de la doble justificación de Seripando no fue aceptada en el Concilio de Trento:

...no debe creer que falta nada a los mismos justificados para que se considere que con aquellas obras que han sido hechas en Dios han satisfecho plenamente, según la condición de esta vida, a la divina ley, y han merecido en verdad la vida eterna, la cual, a su debido tiempo han de alcanzar también, caso de que murieren en gracia. (Cap. 16, 1546, Dz. 809)

La terminología es indecisa y a veces puede dar lugar a equívocos. Pero las discusiones del Concilio dejan las cosas claras. No necesitamos una justificación exterior, que no tenga en cuenta los méritos de los hombres y que se conceda sin tener en cuenta la verdad de la santidad interior del hombre, aunque, por ser gracia, procede finalmente de Dios:

Si alguno dijere que los hombres se justifican o por sola imputación de la justicia de Cristo o por la sola remisión de los pecados, excluida la gracia y la caridad que se difunde en sus 
corazones por el Espíritu Santo y les queda inherente; o también que la gracia, por la que nos justificamos, es sólo el favor de Dios, sea anatema [cf. 799 s y 809]. (Cap. 16, 1561, Can. 11, Dz 821)

Es necesario, por tanto, preguntarnos ahora si esa justificación interior, que puede crecer, necesita de modo absoluto del signo exterior para ser recibida, es decir, del sacramento.

Y la conclusión aparente es no de modo absoluto, ya que Dios lo puede todo, pero sí en la economía histórica de la salvación, ya que Cristo ha ordenado los sacramentos para la salvación del hombre de modo ordinario.

¿Qué puede aportar, aparte de la visibilidad, el signo exterior del sacramento al cambio interior de la gracia?

Es algo tampoco entendido por los protestantes, que, a lo más, conceden a los sacramentos, al menos según la Confessio Augustana que fue el texto tenido en cuenta en Trento por los padres, el valor pedagógico y el valor de explicitación de la gracia interior. Porque esta gracia procede, según ellos, de Dios, al que cree firmemente en Él y en que este instante he sido salvado. Es decir en que la ha recibido.

Nosotros negamos que la fe consista en eso. La fe consiste en creer en el amor de Dios, no en que yo estoy salvado. Eso es la esperanza. Pero, además, también consiste en creer en que el sacramento es necesario para la recepción de la gracia. No es facultativo.

\section{3. ¿Qué aporta el sacramento para la salvación?}

11 menos, hay algo evidente, el sacramento se ve, se percibe, mientras que la gracia no se ve. Ya lo hemos dicho. Pero si la fe no consiste en
creer que estoy salvado, entonces, al menos creeré que he recibido el sacramento de la salvación que da la gracia a quien no pone obstáculo. 
Si el sacramento se recibe con la disposición necesaria, aun mínima, el sacramento actúa eficazmente, porque su autor es Cristo ${ }^{6}$, aunque en la proporción de la disposición humana en cuanto a la 'cantidad' de gracia recibida, cosa que es el tema fundamental de la reciente declaración de la Comisión Teológica Internacional. La fe o disposición es medida de la gracia.

Por tanto, habría que preguntarse si la gracia de Cristo se ejerce a través del sacramento o independientemente de él. Y la respuesta vendría a ser que no independientemente.

Si el sacramento solo aportara su exterioridad, entonces la participación presencial en la eucaristía no sería necesaria.

Sería conveniente, pero no necesaria. Bastaría la participación virtual. $\mathrm{O}$ incluso ninguna.

Algo así pensó Berengario de Tours ${ }^{7}$. Si el pan y el vino permanecen sin variar en sus accidentes es que la sustancia no varía, y, por tanto los sacramentos solo significan lo que ocurre en otra instancia, en el alma del que lo ve. La exterioridad del sacramento no aportaría nada como instrumento, sino solo como signo externo. La doctrina protestante en torno a los sacramentos es muy semejante a la que sugiere Berengario.

6 De acuerdo con el mismo Concilio de Trento: "Si alguno dijere que los sacramentos de la Nueva Ley no contienen la gracia que significan, o que no confieren la gracia misma a los que no ponen óbice, como si sólo fueran signos externos de la gracia o justicia recibida por la fe y ciertas señales de la profesión cristiana, por las que se distinguen entre los hombres los fieles de los infieles, sea anatema" (Cap. 16, 1606, Can. 6, Dz 849). "Si alguno dijere que no siempre y a todos se da la gracia por estos sacramentos, en cuanto depende de la parte de Dios, aun cuando debidamente los reciban, sino alguna vez y a algunos, sea anatema” (Cap. 16, 1607, Can. 7, Dz 850).

"Dices que en este Sacramento el cuerpo de Cristo está presente sin que por ello se cambie la naturaleza o la esencia del pan y del vino, y el cuerpo, que has dicho haber sido crucificado, queda reducido según tú, a una pura ficción mental (PL 142, 1327)” (Ipas, 1991). 


\section{Pero reflexionemos.}

Sabemos que está prohibida la celebración del sacramento de la penitencia sin participación presencial ${ }^{8}$. Y aunque, por otro lado, está permitido el matrimonio por poderes, la indisolubilidad solo se da cuando está consumado, y tal consumación solo se da por presencialidad ${ }^{9}$. Por otro lado sería propio en este caso estudiar bien el sacramento de la eucaristía.

Las especies sacramentales, ya consagradas, no son meras apariencias, son reales accidentes sin sustancia propia. Si fueran meras apariencias no serían accidentes, porque su medición sería mera apariencia, y su hipotético estudio microscópico también. Eso plantea el tema de qué es la sustancia, aunque es claro que esta es la que da lugar a los accidentes, pero la sustancia es algo de tipo metafísico que, en el caso de la eucaristía, es la persona del Verbo Encarnado, Crucificado y Resucitado que se ofreció en la Cruz y se ofrece sacramentalmente al Padre.

Si los accidentes acompañan a una sustancia, y estos son físicos en la eucaristía, donde no están los accidentes no está la sustancia.

8 Véase el Decreto del Santo Oficio, del 20 de junio de 1602, por Clemente VIII: "El Santísimo... condenó y prohibió por lo menos como falsa, temeraria y escandalosa la proposición de que es lícito por carta o por mensajero confesar sacramentalmente los pecados al confesor ausente y recibir la absolución del mismo ausente y mandó que en adelante esta proposición no se enseñe en lecciones públicas o privadas, en predicaciones y reuniones, ni jamás se defienda como probable en ningún caso, se imprima o de cualquier modo se lleve a la práctica” (1994, Denzinger, s.f.).

9 Tiene sentido aquí pensar por qué están prohibidas las manipulaciones en el semen masculino. La historia de esto procede del antiguo mundo romano que reducía el matrimonio al consentimiento. El pecado se caracteriza por el consentimiento, pero a la hora de la práctica resulta difícil saber cuándo se da realmente ese consentimiento libre o no. La historia de la doctrina canónica sobre el matrimonio es bastante aleccionadora sobre la dificultad de saber cuándo se ha dado el contrato matrimonial. Por eso se exigía un signo diferenciador, que después de Trento vino a ser la publicidad, solemnidad litúrgica, y el sacerdote. Aun así, los germanos entendían que todo se consumaba por la unión física. Y así consta en el derecho. 
Es claro que virtualmente, es decir, a través de los medios de comunicación, no se transmiten los accidentes, como no se mete una persona en la cámara y sale por la parte del receptor. Si los accidentes físicos no se transmiten, tampoco la sustancia que va unida a ellos. No se come el pollo que anuncian por el hecho de verlo. Así, no hay accidentes y, por tanto, tampoco la presencia. Y no hay accidentes sino solo percepción de los mismos que se transmite por los medios audiovisuales.

\section{En el protestantismo los sacramentos no tienen cabida}

sto sucede porque no tienen en cuenta al sacramento como
prolongación de Cristo Encarnado y Resucitado. La Humanidad de
Cristo en su contacto con la humanidad de sus discípulos, es decir, con la humanidad de sus ministros y de su Iglesia, es también un dogma, que la reducción intimista e individualista de la Devotio Moderna, que dominó Europa y que influyó sobre el protestantismo, no tuvo suficientemente en cuenta. Y es a partir de dar importancia solo a lo que ocurre en el alma, si ocurre, sin dársela suficientemente a la causa de ello, lo que convierte en fantasmagoría y en sentimentalismo la fe. Ha de resaltarse si ocurre, porque el fariseo de la parábola se creía justificado y no lo estaba y el publicano pensaba que no y sí estaba (Lc 19,9-14). Luego sentir no es suficiente. Más bien equívoco.

La causa de la gracia santificante está en la acción de Dios, habitualmente actualizada por los sacramentos.

Si el ser humano es también carne, es la carne y la materia las que han de ser también redimidas, como la sociedad. Por eso, escándalo para el mundo que pretende adueñarse de la viña, como los labradores homicidas (Mt 21,23-43), es que Dios haya bajado para hacerse cargo de él. 
La lucha de las investiduras dura siempre. Siempre estará en guerra Dios y los poderes del mundo que quieren imponerse. Pero Dios ha entrado. Siempre Dios será, a los ojos de los poderes de este mundo, un intruso. Pero el intruso es el ser humano cuando no obedece a Dios. Cuando hablo de los poderes de este mundo me refiero al mundo en el sentido de uno de los enemigos del alma, a la que quiere dominar.

Cabe reflexionar nuevamente en torno a la gracia, efecto principal del sacramento. La gracia santificante, aunque no es la sustancia del ser humano que es su constitución natural, por ser la gracia sobrenatural, pero sí tiene efectos enormes en el ser humano. La excesiva acentuación de su sobrenaturalidad no debe significar la negación de esos efectos. Los apóstoles salieron distintos del Cenáculo en Pentecostés. Santo Tomás dice que la gracia perfecciona la naturaleza (S. Th, I, C. 1, art. 8, 2001, p. 96).

De modo que la justificación significa un cambio total del hombre, y este hombre cambia su pecado por la alabanza. La alabanza posee un carácter público que vuelve, e incluso manifiesta, la identidad como Pueblo de Dios.

Y es público porque la evangelización es pública. La evangelización es parte de la índole de la Iglesia, porque Cristo se encarnó por el ser humano, y éste es concreto, y por eso la Iglesia siente la pasión por el ser humano concreto y también material, externo y capaz de ser captado por los sentidos. Llegar al ser humano concreto se hace a través de medios externos, la palabra. Y eso es la evangelización cuando esa Palabra procede de Dios, por Cristo. Pero, dentro de ese diálogo con la sociedad, aunque es un diálogo interior, puesto que la comunidad no absorbe al individuo, y los pecados, como los méritos, son también personales, hay también una dimensión pública. Los sacramentos nos unen públicamente a la Iglesia, como la Evangelización 
une en una sola verdad al Pueblo de Dios, a la Iglesia. Todo lo exterior tiene un correlato interior, todo lo visible un correlato invisible y trascendente.

\section{Trento trata los sacramentos en torno a la gracia de la justificación}

in embargo, en Trento no se trató tanto el tema de la Iglesia como $\circlearrowleft$ el tema de la justificación personal, y en eso entraba la concepción protestante de los sacramentos. De alguna forma, la interiorización y personalización, e incluso individualización de la fe que procedía de la Devotio Moderna y de la sensibilidad teutónica, penetró también la reflexión de Trento. Y no solo negativamente. Los sacramentos en Trento son tratados fundamentalmente en torno a la gracia de la justificación, y esta está en relación al pecado personal.

Pero en Trento, herederos por fin de la teología escolástica medieval, que era una cumbre del pensamiento teológico, se ven los sacramentos, después de una enorme evolución intelectual de todo el Medioevo, como instrumentos históricos, es decir, que han penetrado en la historia, y, por eso, también actuales, de la salvación de Cristo, que afecta totalmente al hombre.

Entendamos que eso de penetrar en la historia no significa sólo que el pasado influye en el presente. Lo eterno ha entrado en la historia y la historia ha adquirido algo de lo eterno, porque se ha vuelto ephapax, es decir "para siempre". Lo que ocurrió una vez, en la cruz, se ha vuelto contemporáneo de cada hombre, en cada momento de la historia. No nos extrañemos. San Pablo lo explica en el capítulo cinco de la carta a los Romanos. Ante la cuestión de cómo la muerte de Cristo puede perdonar los pecados de los demás hombres, explica cómo el pecado de Adán perjudicó a 
los demás hombres universalmente, en el espacio y en el tiempo. Es el tema, por demás, a otro nivel, de la carta a los Hebreos.

Por eso, por la unidad humana, lo exterior y lo interior, y lo pasado, lo presente y lo futuro, tienen una estrecha relación. Lo exterior de los sacramentos no es independiente de la realidad interior que contienen y confieren por voluntad y obra de Cristo en una unidad. Tampoco el ser humano puede ser concebido sin tener en cuenta su realidad corporal y su realidad espiritual por separado. Y tampoco esa unidad profunda que posee la humanidad.

Es escandaloso para este mundo individualista, incapaz de ver la profundidad de la trascendencia de cada hombre, que un hombre pueda perdonar los pecados. Pero si no puede, el hombre no ha sido salvado. El hombre, desde la humanidad de Cristo, y por el envío de los Apóstoles, se ha convertido en camino de otro hombre, de todo hombre. Y el cuerpo del hombre se ha convertido en instrumento de su alma. Así, Cristo, que es hombre, utiliza al ministro que también lo es, para salvar a la oveja perdida, a otro hombre.

El dogma de la resurrección de la carne significa la total justificación del ser humano, también en lo corporal, en lo exterior y en lo comunitario. El rebaño del Señor se va reuniendo hasta formar la Jerusalén celestial.

Por eso, aunque los sacramentos tengan como fin fundamental dar la gracia directamente en quien no la tenía, o aumentarla en la persona que ya la tenía, individualmente considerada, y la gracia sea algo fundamentalmente espiritual, la unión en el acto sacramental de lo material y lo espiritual es de tal índole que los hace inseparables.

Por esto se da una armonía con la radical unidad personal de cada ser humano, y se da una armonía con la también radical necesidad del otro, 
del hermano, y del radicalmente Otro, Dios mismo, hecho carne y carne crucificada y resucitada en la Unidad del Verbo Divino.

Porque, en el caso de Cristo, se da una unidad inseparable entre la Persona Divina en Él y la naturaleza humana, con su cuerpo humano y su alma humana. Esa unidad profunda le ha hecho hermano del hombre, hijo de María, primogénito de los muertos. La división de la muerte, que separa de la humanidad al que muere, y le separa su cuerpo de su alma, en Cristo ha sido vencida. Por eso es Cabeza del género humano, cuya vocación es la redención.

Cristo es Dios, pero también hombre. Su cuerpo y su alma humana son instrumento y vehículo de su Persona Divina. Los apóstoles son enviados por Cristo con poder y este poder es sacramental. Luego los sacramentos prolongan en la historia la presencia de Cristo también en cuanto revelado, en cuanto exterior, en cuanto instrumento de la Divinidad del mismo Cristo, ofrecido en la Cruz.

\section{En el sacramento se da la unidad perfecta}

hora bien, en cuanto al sacramento, ¿en qué sentido se da esa unidad
profunda? No es fácil comprender que la gracia del sacramento
esté unida al signo sacramental, ya que estamos diciendo que no actúa solo significándola sino "realizándola" y "otorgándola"10. Ciertamente,

10 Tómese en cuenta nuevamente el canon 6 del Concilio de Trento: "Si alguno dijere que los sacramentos... no contienen la gracia que significan o que no confieren la gracia misma..." (Cap. 16, 1606, Dz 849). Para Hugo de San Víctor, "el agua está en un vaso para poder ser bebida, pero no es el vaso quien la ofrece al sediento, ni menos quien la otorga", por eso los sacramentos contienen, según el autor, la gracia. Santo Tomás, al tomarlos como instrumento de un acto único, pues el acto del sacramento es único, les reconoce que también ellos participan en el otorgamiento de la gracia, y así lo recoge Trento. Esto se ve claramente en el bautismo, pero siempre ha de exceptuarse algunos sacramentos, donde no hay una unidad tan evidente. 
el sacramento es un acto, pero en él hay, al menos, varios principios, no homogéneos entre sí, actuando conjuntamente; por un lado, Dios Trino y el ministro, y, por otro lado, otro principio personal, el sujeto que lo recibe. Como gesto, como acto consciente, lo es en todos esos niveles personales.

Una idea venció todas las dicotomías, la idea del Aquinate indicando las características distintas, pero convergentes, de las diversas causas que confluyen en un acto, destacando en él la causa eficiente y la causa instrumental ${ }^{11}$. La imagen es tan genial y sugerente que no ha sido hasta ahora superada.

El hacha del leñador, aun distinta de su mano, cuando trabaja realiza el mismo acto que la mano y que la persona, así el sacramento realiza el acto de la salvación inseparablemente de Cristo y del Padre a través de la persona del ministro, que actúa como instrumento de la misma. Piénsese, como anteriormente se ha hecho, en la capacidad humana de entrar en la historia ajena, y de Dios de emplearla para entrar en la historia personal. Y

11 Ordeig habla de Rahner y dice lo siguiente: "Comienza, pues, diciendo que «para satisfacer la doctrina de la Iglesia basta con que se retenga que en la administración de los sacramentos se da la gracia por causa del signo sacramental». Continúa lamentándose del poco caso hecho de aquel axioma tradicional en teología: sacramenta significando efficiunt. Y concluye estableciendo ese punto de partida buscado en la reducción de la eficacia sacramental a la mera significación: «Desde el mismo punto de partida se puede hacer comprensible que la eficacia de los sacramentos es precisamente la de los signos: el signo, al significar, lleva consigo lo significado" (1981, p. 66). "La misma "causalidad simbólica instrumental», propia de Schillebeeckx y de Rahner, desemboca, a la postre, en un efecto exclusivamente individual. El sacramento es «una expresión de amor del Hombre Dios» y ese "gesto expresivo de Cristo despierta en nosotros la respuesta... a partir de la cual... podemos realizar el acto teologal del encuentro con Dios en un abandono de fe y de amor»" (1981, p. 68). Ordeig identifica, desde la perspectiva de este artículo, un peligro en la concepción de eficacia en cuanto signo. La inseparabilidad no es la reducción de la obra a la palabra, al signo, porque la eficacia provendría sobre todo de la comprensibilidad del signo, lo que lo acerca peligrosamente al pensamiento protestante. Una cosa es la simultaneidad y otra la dependencia causal de una sobre otra. La eficacia no la da el signo sino el autor. 
en los efectos permanentes de todo acto. Así se comprenderá el horizonte de esta imagen.

No se opone, esta unidad entre sacramento y gracia, a la omnipotencia de Dios, en el sentido de que escandaliza que Dios emplee mediaciones si puede obviarlas.

Que Dios sea omnipotente no significa que no haya previsto las mediaciones humanas, especialmente la de la Encarnación de Cristo y la misma Iglesia, e incluso los actos sacramentales concretos. Su omnipotencia no se opone necesariamente a la concreción de la historia salvífica.

La ley de la comunicación exige compartir el mismo código de comunicación. Los sacramentos son un código, una cita de encuentro en el espacio y en el tiempo. Y es lógico que las normas de ese código las marque Dios, y que sean enormemente concretas, históricas y sacramentales, pues en ellas se trata de llegar, finalmente, al hombre concreto e histórico. Y eso es lo que se suele llamar materia y forma del sacramento, es decir, del signo sacramental, que realiza lo que significa, y que llega a la materialidad del sacramento.

Es cierto que "Deus non alligavit potentiam suam sacramentis [Dios no ha vinculado su poder a los sacramentos]" (S.Th. I-II, C. 113, a. 3, arg. 1, 1993, p. 949) ${ }^{12}$, es decir, Dios no necesita de modo absoluto los sacramentos para salvar al hombre, tal como refiere santo Tomás. Aunque también es cierto que hasta que no se hizo visible, y no solo visible, sino hombre, no salvó a los hombres, y lo hizo por el acto único de la cruz. Histórico, y tan material que Dios, hecho hombre, sufrió la pasión y la muerte.

12 Hasta donde puedo entender, Hugo de San Víctor habló de los sacramentos como vasos que contienen la gracia; Santo Tomás habla de ellos como un acto de Dios y, por eso, la confieren. 
Y, sin embargo, no es la visibilidad lo que hace eficaz el sacramento. Antes bien, su eficacia es visible para que, al aceptar el signo, el ser humano acepte la salvación ofrecida a través de él, llegue a la fe que llega a Dios mismo, sin que el sacramento sea obstáculo para la misma, sino el objeto mismo de la fe en cuanto instrumento.

\section{Todo sacramento es un acto de consagración, dependiente de la cruz}

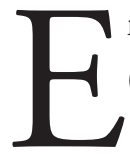

n la cruz, Jesús se consagra al Padre — "Por ellos me consagro Yo" (Jn 17,19-21) - y el Padre devuelve a Cristo Resucitado.

En la eucaristía están el pan y el vino ofrecidos, signo de la consagración y ofrenda orante de la vida de los participantes; y una vez consagrado dicho signo, recibe en correspondencia la devolución del mismo, convertido en Cristo; y, con Él, y por la comunión, los participantes que se ofrecieron con el pan y el vino; es decir, que, por la comunión, dice la oración de la Iglesia, quedan tan profunda y realmente unidos a Cristo que se convierten, de algún modo, en lo que reciben ${ }^{13}$.

También en los demás sacramentos hay una consagración, una muerte, una ofrenda a Dios por la fe, unida a Jesús en la cruz, que recibe posteriormente del Padre la respuesta de la gracia. Como Isaac ofrecido por Abraham y recobrado después, vivo, con una bendición, así es ofrecido el niño en el bautismo, para recuperarlo libre de pecado, lo mismo el cristiano en cada sacramento para recibir de Dios la vida bendecida. Todo ello se hace en la tierra, y por eso visiblemente, para recibir, invisiblemente, la eficacia del cielo. El sacramento une el cielo con la tierra.

A pesar de ello, y no pudiendo despreciar impunemente los sacramentos de Cristo, Dios puede dar su gracia a los no bautizados que sin

13 Postcomunión de la memoria de san Agustín. 
culpa desconocen el Evangelio, como dice el Vaticano II $^{14}$, porque ellos no son responsables de su ignorancia respecto de los medios de santificación; pero habitual y plenamente, y, dirían los cristianos, más evidente y específico, lo hace a través de los sacramentos de la Iglesia. Cabría añadir algo más: en virtud de los sacramentos, y a la espera de recibirlos. Si el sacramento está unido profundamente con la Pasión de Cristo, y es en virtud de ella que se da invisiblemente la salvación del hombre a los que no pueden recibir de hecho los sacramentos, esta salvación está unida también invisiblemente tanto a la Pasión como a los sacramentos que proceden de ella. Por tanto, a la espera de recibirlos.

¿Qué puede aportar lo visible a lo invisible, lo histórico a lo sobrenatural, lo material a lo espiritual? No solo la significación, es decir la visibilidad, y, en este sentido, la comunicabilidad histórica, sino, además, la Encarnación, es decir, la llegada y la unión de lo visible y lo Invisible, lo social y humano con Dios. E incluso, en este sentido, la unidad de la Evangelización con su contenido. La Evangelización consiste en la transmisión de la Buena Noticia. La Noticia consiste en la entrada en la historia del misterio de Dios. Eso es el sacramento.

El aspecto comunitario de los sacramentos es, todavía, una asignatura pendiente de la Iglesia y enormemente actual. Ahí entran también ambos aspectos del sacramento, la eficacia y la significatividad. El signo no obra por sí mismo, sino que su eficacia está en lo significado, y lo significado es real, y si es una noticia, no es simplemente una promesa, porque al transmitir la noticia se transmite su actualidad y la posibilidad de llegar a lo que la noticia transmite. Y, como todo sacramento está relacionado con el

14 "Los que sin culpa suya no conocen el Evangelio de Cristo y su Iglesia, pero buscan a Dios con sincero corazón e intentan en su vida, con la ayuda de la gracia, hacer la voluntad de Dios, conocida a través de lo que les dice su conciencia, pueden conseguir la salvación eterna LG 16" (Catecismo de la Iglesia Católica, n. 847, 1997). 
Misterio Pascual, con el doble movimiento de ofrecer y recibir, de orar y ser escuchado, la noticia convierte la posibilidad en realidad a la que es posible acceder.

Pero, como la significatividad y la transmisión de la verdad operan a través de la índole social del ser humano, también la significatividad sacramental tiene una índole comunitaria.

Concretando, no sólo se me hace saber a mí lo que sucede en mi alma. Yo lo recibo a través del sacramento. Y este sacramento por la Iglesia. Es decir, desde fuera, por un acto realizado por otro. Por (volviendo al símil tomista) un hachazo en la historia que transforma el árbol en algo capaz de prestar un servicio al ser humano.

Y también la Iglesia, representada por el ministro, que es, al mismo tiempo, profeta para el cristiano, ora con este y se nutre de lo que el mismo cristiano recibe. Es más, toda la comunidad vive y se nutre de lo mismo. Es cierto que de modo distinto, pues cada rama, injertada en el olivo, recibe particularmente la savia del olivo, pero todo el olivo se alegra, y aquello que aporte esa rama a todo el olivo ayuda a todo el olivo.

\section{Aplicándolo a la pandemia}

7 ste es un mundo muy comunicado. Como nunca lo estuvo. Y las personas están, desde la pandemia, perfectamente conscientes de que es una aldea global.

Pero quizá, a pesar del sentido de mutua pertenencia que actualmente, contra todas las tendencias egoístas, nos invade, no hemos sido tan conscientes de que Dios quiera salvar al mundo entero, que la caridad, y la salvación total y universal, no puede estar separada de la misma salvación individual, que la Iglesia no puede estar separada de los sacramentos, y que 
la visibilidad de los mismos, así como el diálogo con Dios que suponen, no está separado de la evangelización por la que nos convertimos y nos acercamos a ellos. Hay una unidad que resalta esa responsabilidad a la que nos invita la pandemia actual, y que tiene su reflejo en la reciente declaración de la Comisión Teológica Internacional, que insiste en la unidad de evangelización y sacramentos, en la unidad, y casi equivalencia, entre el diálogo personal con Dios que es la fe, y el diálogo sacramental con Dios, que es también la fe como respuesta a su amor.

Esa realidad comunitaria y sacramental, externa e interna, que aparece en la alegoría de la vid en Jn 15, presenta la vida divina de la gracia como una participación de la savia de la misma vid. Por eso, aquello que, a una mirada superficial, aparece como algo absolutamente individual, resulta ser una participación de una realidad que supera lo individual. Y la vid, en la que hay muchos sarmientos, que, unidos entre sí a través de su tronco, tienen vida, nos invita a pensar, con san Pablo, que se trata, por tanto, de la misma vida divina que está en la Iglesia, de la caridad que los une, y que, sin la Iglesia, es imposible participar de esa vida.

La índole de la Iglesia es comunitaria. Participar de la Cabeza es vivir como Cuerpo de Cristo, como Iglesia. De ahí la importancia de la unidad que suplica Jesús al Padre en el día de su muerte, según san Juan. Es el objetivo de la vida de Jesucristo: unir a las personas entre sí con el Padre, por Cristo, en el Espíritu.

El cemento que une y el vehículo que enlaza todo son los sacramentos de la Iglesia, pues en ellos se hace presente Jesucristo, y la Jerarquía que nos pastorea, también, según san Ignacio de Antioquía, es símbolo e instrumento de la unidad del único Pastor. 
Benedicto XVI ha insistido mucho, en su Spe Salvi, en el destino de la gracia santificante a la comunión del Cuerpo de Cristo, que es la Iglesia. La gracia, que pone al cristiano en relación con la Cabeza y el Cuerpo, y, por eso, el sacramento, que es su instrumento, será así entendida siempre como el fruto de una celebración pública y comunitaria de la misma Iglesia.

Es la Iglesia la que recibe, a través del mismo sacramento, en su seno, al bautizado, al pecador arrepentido, la que une en la misma carne y sangre del Salvador a sus miembros en la eucaristía. Y la Iglesia es radicalmente visible, además de invisible. Todo sacramento es público, y une con Cristo, aunque sea para recibir las fuerzas necesarias para vivir la misión propia, por ejemplo, del matrimonio. Y aquí está, no solo la oración de la Iglesia, que intercede, sino también la respuesta a la intercesión, en un solo acto. Pues el cuerpo visible es instrumento del alma invisible, y Cristo y la Iglesia son, como Cuerpo, elementos de una continuidad inseparable. Jesucristo ora en su Iglesia ante el Padre. Intercede. La Iglesia visible y su oración se convierten también en instrumento del Señor invisible, que ha vencido al mundo ${ }^{15}$.

Sacaremos las conclusiones de todo ello.

\section{9. ¿Qué aporta realmente el sacramento a la contrición perfecta?}

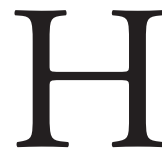

ay una pregunta que debe hacerse: si el deseo de confesarse con la debida disposición con contrición perfecta perdona antes de confesarse, ¿qué aporta el mismo sacramento?

15 Por algo se les pide a los presbíteros que impongan las manos sobre el que se ordena como tal. Debe haber en la Iglesia, aunque jerárquicamente ordenada, una unidad con la Cabeza que la hace toda ella, no separadamente de su jerarquía, pero tampoco al contrario, capaz de otorgar el sacramento. 
Hay un atisbo de solución a la pregunta en la obligación de confesar los pecados y recibir la absolución cuando el que se ha arrepentido y no se ha podido confesar tiene ocasión posterior de hacerlo.

Porque si, después, la Iglesia pide que se digan los pecados en confesión y se reciba la absolución, es que algo aportaría el sacramento que no lo habría dado la contrición perfecta. Luego debe haber algo en el sacramento que no lo tiene el simple deseo del sacramento, aunque vaya acompañado de una contrición perfecta

¿Debería de aplicarse esto a todos los sacramentos?

Es interesante constatar cómo el Concilio de Trento entiende que el deseo es específicamente deseo del sacramento, como mediación de la gracia inseparable de ella, no simplemente deseo de la gracia del sacramento (o la fe en el amor de Dios que justifica, lo que vendría a ser la posición de los reformados), y, por ello, declara necesario el sacramento y no solo la fe, para la justificación del hombre. Es claro que esto afecta especialmente a los sacramentos llamados necesarios, aunque la necesidad de los sacramentos se afirme de todo el organismo sacramental ${ }^{16}$. Hay un consenso logrado actualmente, según la Declaración Conjunta católico-luterana sobre la Justificación ${ }^{17}$.

16 "Si alguno dijere que los sacramentos de la nueva Ley no son necesarios para la salvación, sino superfluos, y que sin ellos o el deseo de ellos, los hombres alcanzados de Dios, por la sola fe, la gracia de la justificación, aun cuando no todos los sacramentos sean necesarios a cada uno: sea anatema" (Can. 4). "Si alguno dijere que el impío se justifica por la sola fe, de modo que entienda no requerirse nada más con que coopere a conseguir la gracia de la justificación y que por parte alguna es necesario que se prepare y disponga por el movimiento de su voluntad: sea anatema" (Can. 9). "Este texto reafirma el convencimiento de la fe católica respecto de la necesariedad de la mediación sacramental para lograr la gracia de la justificación, no siendo la sola fe suficiente" (Podestá, 2020, p. 3).

17 "Los reformadores pusieron un énfasis particular en ello: En medio de la tentación, el creyente no debería mirarse a sí mismo sino contemplar únicamente a Cristo y confiar tan solo en él. Al confiar en la promesa de Dios tiene la certeza de su salvación que nunca 
$\mathrm{Al}$ menos hay algo que el que no se bautiza, aunque vaya al cielo porque muere con el deseo del bautismo, no tendría en la tierra, el carácter. Y esto porque el bautismo aporta una participación en la Iglesia a la que parece estar unido el carácter, al que santo Tomás llama "deputación para el culto divino". A eso se le llama res et sacramentum ${ }^{18}$.

Los sacramentos tienen, en general, este elemento, la res et sacramentum, aparte del signo sacramental, o sacramentum, y de la gracia o res. En el caso del bautismo, confirmación y orden, se trata del "carácter", y en el caso de la eucaristía la misma Presencia Real de Cristo en ella. Se trata de algo, distinto de la gracia, que la exige, y en todo sacramento de algún modo se encuentra y es signo e instrumento de la gracia que se recibe. El carácter del bautismo, por otro lado, nos exige constantemente la fidelidad al Señor. Lo mismo ocurre con el de la confirmación y el del orden. Porque no se pierde; como no pierde su carácter, es decir, su filiación de hijo, el Pródigo, por muy lejos que esté de su Padre ${ }^{19}$.

tendrá mirándose a sí mismo” (Declaración Conjunta N. 35).

18 "A partir de la terminología empleada por S. Agustín, la teología del siglo XII, elabora el concepto res et sacramentum, con el fin de señalar que, en la dinámica operativa del sacramento, entre la realidad externa, visible — sacramentum tantum-y la gracia causada por el sacramento - res sacramenti- es preciso situar una realidad intermedia, directamente causada por el signo sacramental externo, por lo cual es denominada res, $\mathrm{y}$, al mismo tiempo sacramentum, por ser signo y causa de la gracia, como ultima res contenida en los efectos sacramentales... Y precisamente a partir de la estabilidad típica del carácter, se percibe el rasgo más representativo quizá de la res et sacramentum, según la doctrina de Santo Tomás: el de sacramentum permanens" (Tejero, pp. 428-429).

19 "En un momento histórico, en que la eclesiología aún no ha encontrado un lugar propio entre las partes que vertebran la teología sistemática, la res et sacramentum resulta ser, entre las piezas que integran la síntesis realizada por Santo Tomás en su doctrina sacramentaria, la más adecuada para la comprensión de la estructuración básica de la Iglesia... A partir de este dato esencial, debe hacerse notar la imperfección metodológica que, a nuestro entender, han cometido los teólogos posteriores al Aquinatense en la consideración de la res et sacramentum. En efecto, habiendo limitado tantas veces la consideración de los sacramentos al ámbito de su capacidad para causar la gracia, incurrieron en el error 
Pongamos un ejemplo, una persona puede casarse y no estar en gracia santificante. En consecuencia, el sacramento, válido, no aumentaría su gracia, porque este sacramento la aumenta si existe. Pero se da, sin embargo, el vínculo indisoluble cuando el sacramento se ha consumado con la unión marital. Una vez se da ese vínculo, independientemente de la gracia, el matrimonio rato y consumado es indisoluble hasta la muerte de uno de los cónyuges.

El vínculo es un don del sacramento, la res et sacramentum, que no depende del grado de disposición del sujeto, con tal de que desee recibir el sacramento. Por eso no se repite el matrimonio, ni el bautismo, ni la confirmación, ni la ordenación sacerdotal. Tienen el carácter, aunque no

de entender que vendría legitimada la existencia de la res et sacramentum solamente en la medida en que tal elemento sacramental estuviera requerido por la misma gracia. Antes de pasar a la consideración directa de la doctrina de Santo Tomás, es conveniente tener en cuenta el referido error de método, que manifiesta una visión intimista de los sacramentos, incapaz de percibir la importantísima dimensión eclesiológica que brota de las diversas situaciones originadas a partir del sacramentum permanens, que contiene la res et sacramentum, y que Santo Tomás traduce en conceptos de tanta relevancia jurídicocanónica, como deputatio, potestas pasiva, potestas activa, officium, relatio..., a través de los cuales, se percibe una estructuración de diversas situaciones jurídicas mutuamente relacionadas. En ellas, concurren todas las características básicamente configuradoras de la Iglesia, en la común condición cristiana y en la variedad de funciones y oficios, que, en la misma naturaleza sacramental de su origen, tienen todas las notas de la operatividad propia del orden jurídico: la exterioridad de situaciones derivadas del signo sacramental, que en sí mismas tienen carácter de signo; la tipicidad de su contenido perfectamente delimitado al margen de las variables personales; la alteridad derivada del carácter complementario de tales situaciones mutuamente relacionadas; la exigibilidad de las prestaciones dimanantes de las respectivas deputaciones sacramentales... Y, ciñendo la unidad de sentido que las diversas situaciones jurídicas dimanantes de los sacramentos encierran, la res et sacramentum de la Eucaristía se presenta como el fin a que se ordenan todas las deputationes, officia, relationes o potestates, que alcanzan su plenitud de significado en la ordenación de los diversos munera, que se prestan siempre en la comunidad de los cristianos, en tendencia hacia la communio corporis Christi" (Tejero, 2020, pp. 427; 431). 
tengan la gracia. También recibe a Cristo quien comulga con pecado mortal, pero la recepción de Cristo no le santifica.

Los sacramentos se consuman no por el deseo, sino por la misma recepción. Y vinculan a Cristo y a la Iglesia todos ellos a modo de alianza, teniendo ésta un efecto que es la res et sacramentum.

Por tanto, reducir el sacramento a la formalidad externa del perdón, alcanzado antes por la fe y la conversión, sería falso. Mi fe no logra el perdón. Es Cristo quien lo da. Mi fe cree en lo que Cristo me quiere dar y yo lo recibo fundamentalmente de modo pasivo, gratuito, aunque mi fe desee recibirlo. Por eso el sacramento no sirve para comunicarme algo que ya recibí, sino para darlo. Porque en él está Cristo dándomelo. Si se me anticipa es porque después se me confirma. Tal confirmación es definitiva porque permite unirme a la Iglesia, que de por sí es exterior y visible, y, a la vez interior e invisible. Cuerpo Místico de Cristo. Luego no se trata de algo prescindible, inútil.

La fe es en el sacramento, y de por sí, debe llegar a recibirlo, es decir, la fe está abocada a la recepción del sacramento que da la gracia. La impresión es que el sacramento futuro da la gracia como en el caso de María ("ante praevisa merita Christi"), en previsión del futuro sacramento al que desea recibirlo.

La fe protestante parecería ser una fe en Cristo Salvador que excluye los medios que Cristo ha dejado para la salvación. Esto es en teoría, en la práctica entre los evangélicos se practica la bendición y la oración. Ambas suponen un momento distinto a la fe. El momento en que Dios da el don. Y ese momento, entre los católicos se llama sacramento si el don que se pide es el de la gracia de ese sacramento. 
Dejando de lado, pues, la fe protestante en la salvación, que no contempla en principio la necesidad de los sacramentos, respondamos a la pregunta: ¿Es indiferente la recepción de los sacramentos, o la celebración presencial de los mismos, respecto de la gracia que se recibe a través de ellos? Dicho de otro modo, ¿`se recibe igual la gracia si se está presente corporalmente en el templo donde se celebra el sacramento que si se asiste a él virtualmente?

No es indiferente la presencia corporal. Y no lo es porque no es indiferente recibir el bautismo aunque haya precedido la fe que salva, la fe informada por la caridad. Tampoco lo es confesarse y recibir la absolución aunque haya precedido la contrición perfecta. Porque la fe lo es en lo que voy a recibir, y no puedo decir que me es indiferente recibirlo o no. Como no lo es el cumplimiento de la promesa para quien espera algo, aunque pudiera recibir un anticipo de lo que espera; y, como tampoco lo es, comulgar realmente con el Cuerpo y la Sangre de Cristo o desear hacerlo.

\section{0. ¿Se da la misma gracia con la recepción que con el deseo del sacramento?}

$\mathrm{P}$

ero surge naturalmente una pregunta, derivada de la anterior: ¡la gracia que se concede al cristiano por la recepción de los sacramentos es la misma que la que se le concede por el deseo de los mismos?

Es claro que si la gracia, que es el fin personal de los sacramentos, no fuera la misma, no se daría un anticipo de la misma gracia (en el caso del bautismo, la salvación y el perdón de los pecados, o sea, la aplicación de la redención). Debería ser la misma. Pero si fuera la misma, ¿qué aportarían los sacramentos excepto su solemnidad, su visibilidad? 
Tal vez ya se formuló una respuesta a la pregunta anterior: el carácter, que une a la Iglesia, y la alianza histórica con Dios, que no se hizo hasta que Dios firmó, visiblemente, esa Alianza, deseada por ambos. En algún sentido, se dice que los hombres están salvados en esperanza (Rom 8 , 24-28). Es decir, el sacramento, a imitación del cielo, da lo que la esperanza anticipa.

Pero creo que aquí hemos de decir que cada sacramento es distinto. Si en los demás sacramentos la transformación del ser humano se da, en la eucaristía la unión es máxima porque viene el mismo Señor, y no solo su fuerza, su dynamis, a tomar posesión del hombre.

Pero en la comunión espiritual se desea y se lamenta que todavía no se dé esa posesión, esa transformación interior por la que el hombre se une a Cristo crucificado y resucitado del modo con que se da en la comunión eucarística, justamente porque no se recibe sacramentalmente. O sea, se da la esperanza.

Cuál sea esta unión, por la que el agonizante recibe la comunión como viático para la vida eterna, queda en el misterio aunque el misterio de la misma Iglesia, que hace actual en los sacramentos la salvación, operada en la cruz, algo nos dice.

Por eso, debe haber alguna diferencia entre desearlo y recibirlo. En los sacramentos que imprimen carácter, al menos, la diferencia es que la recepción efectiva produce el carácter y el deseo del sacramento no. Y en el matrimonio el vínculo. Ese vínculo no solo les hace pertenecerse a los cónyuges, sino que les une indefectiblemente al que dijo: "Lo que Dios ha unido”. Dios firma la alianza.

Si la plenitud de los sacramentos es la eucaristía, todo lo anterior se debe dar en ella de modo eminente. Podría decirse con una palabra: la 
pertenencia a Cristo y, por esa unión, a Dios Padre, en el Espíritu Santo, aunque en esperanza, puesto que se puede perder.

Y eso lo debe dar el conjunto eucarístico de la ofrenda, consagración y comunión, por la que Dios acepta el sacrificio de su Hijo al que se une a la Iglesia, realmente, a través de la comunión, y, aceptado, le entrega todo al Hijo: "Se me ha dado pleno poder" (Mt 28,19). Nosotros nos entregamos y somos aceptados y, en ese momento, somos suyos.

Hay una objeción. Si le pertenecemos, ¿por qué vamos a recibirle muchas veces? Porque se puede perder. Porque somos libres e históricos, porque hoy negamos lo que ayer profesábamos. Porque pecamos.

El símbolo de la comida expresa lo que ocurre. Como el alimento se une con el que lo recibe hasta el punto de la identificación, así Cristo nos asume al modo trinitario. Somos distintos pero una sola cosa. No obstante, así como la historia impide que una comida sirva para siempre, así, el ser humano, capaz de libertad, debe realizar muchas veces la entrega a Dios que es la eucaristía, porque también muchas veces podría abandonarle.

En este sentido, la eucaristía es sacramento que ayuda a la fidelidad. También habría que exceptuar a esto que estoy diciendo la muerte martirial. Si la eucaristía es ofrecerse incruentamente con Cristo que murió cruentamente, la muerte martirial es tal identificación con Cristo que debe lograr todos los dones de la eucaristía, y no se repite porque el mártir se entrega de una vez para siempre. Quizá por eso se dé el Viático a los que luchan en la tentación tremenda de desesperación que es la agonía, que significa combate. Hay una entrega a Dios en el combate de la muerte, donde se lucha contra la desesperación, y ese momento es calificado en Trento — si en él vence la gracia divina — como el máximo don, el don de la 
perseverancia final, don que hay que pedir constantemente como hacemos en el Ave María, "ahora y en la hora de nuestra muerte"

San Agustín lo testifica así:

Quienes, en efecto, mueren por confesar a Cristo sin haber recibido el bautismo de la regeneración encuentran en la muerte tal poder para remisión de sus pecados como si fueran lavados en la sagrada fuente del bautismo. Pues quien dijo: «A menos que uno nazca del agua y del espíritu, no puede entrar en el reino de Dios», exceptuó a éstos en otro pasaje, donde habla con idéntica generalidad: "Al que me confesare delante de los hombres yo también le confesaré delante de mi Padre, que está en los cielos»; y aún en otro lugar: «El que pierda su vida por mí la encontrará». (s.f., Libro XIII, n. 7)

Se me dirá que ahí san Agustín no habla directamente de la eucaristía sino del bautismo de sangre, pero también le diría yo que la relación del bautismo con la eucaristía es la de los tres sacramentos de iniciación, es decir, de identificación con Cristo, de los que la eucaristía constituye su culminación. De hecho, los mártires nunca necesitaron otra cosa para ser considerados santos.

20 El Segundo Concilio de Orange, en 529 A.D. enseña, contra la posición de los semipelagianos, que los que han sido justificados también deben orar constantemente por la ayuda de Dios para tener un buen fin (Denzinger, 380). El Concilio de Trento, en 1547 llama a la perseverancia "un gran don" y dice que los que están en estado de gracia no pueden persistir en amistad con Dios sin especial ayuda divina (Denzinger, 1572). La perseverancia final es un don que estrictamente no merecemos. Aun si en la actualidad estamos en gracia, no podemos saber con certeza si vamos a perseverar (a no ser que recibamos una revelación especial al respecto) (Trento, Denzinger, 1566). Por cierto, aunque no estuvieran cuando se celebró la Misa los que comulgan fuera de ella, por la Comunión recibida fuera de la Misa, se unen con la Misa que se celebró. 
En el caso que nos ocupa, el COVID-19, hemos de decir que no podemos dejar de lado la necesidad de los sacramentos, porque, en ese caso, dejaríamos de lado la misma Encarnación de Cristo, por la que se hizo una sola cosa, también histórica y comunitaria, es decir, eclesialmente, con nosotros.

\section{REFERENCIAS}

Benedicto XVI. (2007). Carta Encíclica Spe Salvi del Sumo Pontífice Benedicto XVI a los obispos, a los presbíteros y diáconos, a las personas consagradas y a todos los fieles laicos sobre la esperanza cristiana. La Santa Sede. https:/www.vatican.va/content/benedictxvi/es/encyclicals/documents/hf_ben-xvi_enc_20071130_spesalvi.html

Catecismo de la Iglesia Católica. (1997). La Santa Sede. https://www. vatican.va/archive/catechism_sp/p123a9p3_sp.html

Comisión Teológica Internacional. (2020). La reciprocidad entre fe y sacramentos en la economía sacramental. La Santa Sede. https:// www.vatican.va/roman_curia/congregations/cfaith/cti_documents/ rc_cti_20200303_reciprocita-fede-sacramenti_sp.html

Concilio de Trento. (s.f.). Sesión VI. Decreto sobre la justificación. Cap. 16. Del fruto de la justificación, es decir, del mérito de las buenas obras y de la razón del mérito mismo. Clerus. Congregación para el Clero. http://www.clerus.org/bibliaclerusonline/es/ffq.htm 
Denzinger, H. J. D. (s.f.). Magisterio de la Iglesia III. Desde Pío IV hasta Clemente XI. Clemente VIII, 1592- 1695. De la absolución del ausente. Enchiridion Symbolorum. Catholic.net. http://es.catholic. net/op/vercapitulo/2824/redireccion.html\#IV

Eggers Lan C. \& Juliá, V. E. (Trads.) (1981). Jenófanes. Los filósofos presocráticos I. Gredos. https://www.pieresko.net.ar/libros/Gredos/ Los\%20Fil\%C3\%B3sofos\%20Presocraticos\%20I.pdf

Ipas, J. (1991). Berengario de Tours. Gran Enciclopedia Rialp. Editorial Rialp. https:/www.mercaba.org/Rialp/B/berengario_de_tours.htm

Ordeig, Manuel J. (1981). Significación y causalidad sacramental según Santo Tomás de Aquino. Scripta Theologica, 13(1), pp. 63-114. https://core.ac.uk/download/pdf/83565259.pdf

Podestá, A. (2020). El sacramento de deseo. Breve aporte para pensar el acceso a los sacramentos en tiempos de Aislamiento Social, Preventivo y Obligatorio por COVID-19. Sociedad Argentina de Teología. sociedadargentinateologia.org/wp-content/uploads/2020/05/ Podestá-Agustín-El-sacramento-de-deseo.pdf

San Agustín de Hipona. (s.f.). De Civitate Dei. Sant'Agostino. Augustinus Hiponensis. https:/www.augustinus.it/spagnolo/cdd/index2.htm

San Ambrosio de Milán. (2005). Explicación del símbolo. Los sacramentos. Los misterios (Introd., trad. y notas de P. Cervera). Editorial Ciudad Nueva.

Santo Tomás de Aquino. (1993). Suma de Teología II. Parte I-II (2. a ed.). Biblioteca de Autores Cristianos. Dominicos.org. https://www. dominicos.org/media/uploads/recursos/libros/suma/2.pdf 
Santo Tomás de Aquino. (2001). Suma de Teología I (4. ${ }^{a}$ ed.). Biblioteca de Autores Cristianos. Dominicos.org. https://www.dominicos.org/ media/uploads/recursos/libros/suma/1.pdf

Tratado general de los sacramentos. Condensación del libro de Arnau para uso privado de los alumnos de la asignatura "Teología de la Liturgia y de los Sacramentos” Curso 2009/2010. (s.f.). Ramón Navarro Gómez. http://www.rnavarro.info/resources/Condensacio\%CC\%81nlibro-Arnau.pdf

Tejero, E. (1983). La "res et sacramentum", estructura y espíritu del ordenamiento canónico. Síntesis doctrinal de Santo Tomas. En Rodríguez, P. (Ed.), IV Simposio Internacional de Teología de la Universidad de Navarra. Servicio de Publicaciones de la Universidad de Navarra. https://dadun.unav.edu/handle/10171/6290 
